\title{
C-H Zincation of (Hetero)Arenes Followed by Copper-Catalyzed Amination
}
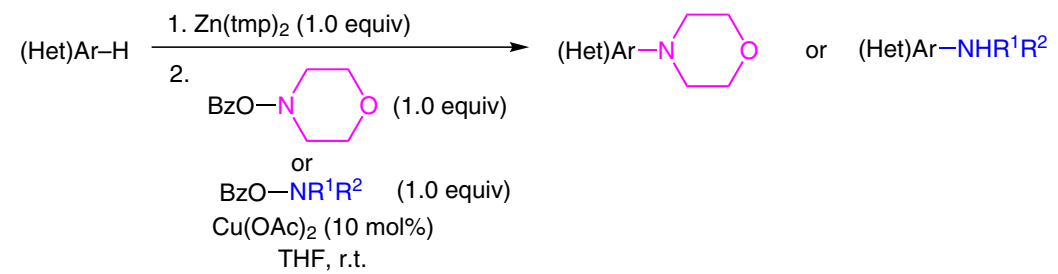

Selected examples:<smiles>[Y10]c1nc2ccccc2n1N1CCOCC1</smiles>

$96 \%$ yield<smiles>[R16][NH+]1CCCN(c2nc3ccccc3n2C)CC1</smiles>

$76 \%$ yield<smiles>c1coc(N2CCOCC2)n1</smiles>

$92 \%$ yield

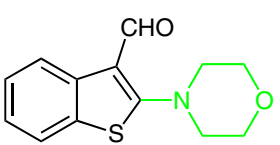

$86 \%$ yield

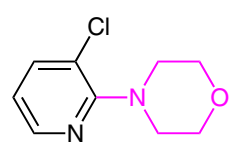

$81 \%$ yield

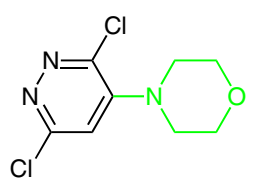

$90 \%$ yield<smiles>CCOC(=O)C1CCN(c2nc3ccccc3s2)CC1</smiles>

$79 \%$ yield

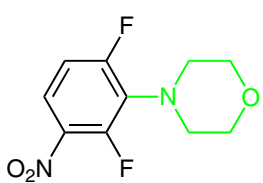

$98 \%$ yield
Significance: Wang and co-workers describe a direct amination of (hetero)arenes by $\mathrm{C}-\mathrm{H}$ zincation followed by copper-catalyzed electrophilic amination using $\mathrm{O}$-acyl hydroxylamines. A broad substrate scope, good functional-group tolerance, and mild reaction conditions were demonstrated.
Comment: The $\mathrm{C}-\mathrm{H}$ zincation was achieved applying either $\mathrm{Zn}(\mathrm{tmp})_{2}$ or tmpZnCl. LiCl (tmp = 2,2,6,6-tetramethylpiperidyl) at room temperature. The obtained products were isolated in good to excellent yields. 